\title{
Perbaikan Desain Kemasan Produk Biskuit Brownies Menggunakan Metode Quality Function Deployment (QFD)
}

\author{
Redesign of Brownies Biscuit Packaging using Quality Function Deployment (QFD) Method \\ Maimunah Hindun Pulungan, Lisha Dwi Hastari*, Ika Atsari Dewi \\ Department of Agro-Industrial Technology, Faculty of Agricultural Technology, Brawijaya University \\ Jl. Veteran, Malang, 65145, Indonesia \\ *Email: lishadwihastari@email.com
}

Diterima: 9 September 2019; Disetujui: 10 Desember 2019

\begin{abstract}
ABSTRAK
UKM Canggi Fully merupakan industri yang memproduksi biskuit brownies Cripyx yang dikemas dalam bentuk standing pouch berwarna merah berisi 60 gram. Penampilan desain visual yang kurang menarik serta bahan kemasan kurang tebal dan kokoh sehingga produk mudah patah dan pelanggan ragu membeli produknya. UKM ingin memperluas segmentasi pasar dan memenuhi permintaan pelanggan maka dilakukan perbaikan desain kemasan biskuit brownies menggunakan metode Quality Function Deployment (QFD) sehingga diketahui atribut tingkat kepentingan pelanggan, respon teknis yang dapat dilakukan produsen dan desain kemasan yang diterima pelanggan dan produsen. Hasil penelitian menunjukkan atribut yang diinginkan pelanggan adalah kapasitas produk, desain grafis, dimensi, bentuk, kekuatan dan ketahanan kemasan. Respon teknis yang dapat dilakukan produsen adalah desain visual modern, warna kemasan menarik, gambar produk dan kejelasan informasi, dimensi sesuai kapasitas, kapasitas produk lebih banyak, bentuk kemasan ergonomis, bahan kemasan lebih tebal, tahan tumpukan dan tidak mudah rusak. Rancangan desain kemasan biskuit brownies yang diterima produsen yaitu, kemasan toples berbentuk persegi panjang sebagai kemasan primer dilapisi kemasan sekunder dengan bahan kertas art paper dengan gramatur kertas 260 gram dan bagian luar kertas diberi laminasi doff. Dimensi kemasan yang digunakan memiliki panjang $14 \mathrm{~cm}$, lebar $8 \mathrm{~cm}$, dan tinggi $7 \mathrm{~cm}$, dengan perpaduan warna krem, cokelat dan merah serta memiliki kapasitas 280 gram.
\end{abstract}

Kata kunci: Biskuit Brownies; Quality Function Deployment; Redesain Kemasan

\section{ABSTRACT}

Canggi Fully SME is the industries that produce biscuit brownies Cripyx packaged in red standing pouch with 60 gram contents. This packaging has a less attractive packaging design appearance and the packaging material is not thick enough and sturdy so the product will easily break and customers hesitate to buy it. In order to expand market segmentation and fulfil market demand to make more attractive premium packaging using Quality Function Deployment (QFD) method to determine the attributes of customer interest, to find out the technical responses that must be done by the manufacturer and to find out the brownies biscuit packaging design accepted by customers and the SMEs. The results showed the attributes that customers wanted are product capacity, graphic design, dimensions, shape, strength and durability of the packaging. The technical responses are modern visual design, attractive colors, clear information, dimensions according to capacity, more product contents, ergonomic packaging forms, thicker and stack-resistant packaging materials that are not easily damaged. Brownies biscuit packaging designs that accepted by manufacturer are the form of rectangular as primary packaging and packed up with secondary packaging using art paper material with 260 gram paper and the outside of the paper was given doff lamination. The dimensions of the packaging are $14 \mathrm{~cm}$ length, $8 \mathrm{~cm}$ width and $7 \mathrm{~cm}$ height, with a beige, brown, and red colour and the capacity of 280 grams.

Keywords: Brownies Biscuits; Quality Function Deployment; Re-design Packaging

\section{PENDAHULUAN}

Aspek visual menjadi daya tarik yang sangat penting dalam pembuatan desain kemasan untuk menarik perhatian pelanggan kepada suatu produk sehingga para pelaku bisnis perlu memperhatikan desain kemasan produknya. Dari segi promosi, kemasan berfungsi sebagai perangsang atau daya tarik pembeli dimana desain kemasan yang kurang menarik akan menyebabkan penurunan kualitas produk dan begitu juga sebaliknya. Desain kemasan sendiri merupakan sebuah bisnis kreatif yang mengaitkan bentuk, struktur, material, warna, citra, dan elemen-elemen desain dengan informasi produk agar produk dapat dipasarkan (Fitriah, 2018). Salah satu produk makanan yang dikemas adalah biskuit. Menurut Pusat Data dan Sistem Informasi
Pertanian (2015), minat masyarakat Indonesia terhadap kue kering khususnya biskuit sangat tinggi yaitu sebesar 24,22\% per tahun 2011-2015. Berbagai jenis biskuit banyak dijual di pasaran salah satunya adalah biskuit brownies. Biskuit brownies merupakan inovasi olahan kue brownies yang dipotong tipis sehingga membentuk tekstur renyah seperti biskuit.

UKM Canggi Fully adalah salah satu UKM yang memproduksi biskuit brownies dengan merek dagang Cripyx. Saat ini biskuit brownies Cripyx hanya dikemas dengan kemasan primer berbahan aluminium foil dengan bentuk pouch berwarna merah dengan tambahan stiker untuk memberikan informasi produk. Kemasan biskuit brownies Cripyx saat ini memiliki penampilan yang kurang menarik karena desain kemasan yang terlalu sederhana 
serta bahan kemasan yang kurang kokoh sehingga produk di dalamnya patah sehingga pihak pelanggan menjadi ragu untuk membeli produk tersebut.

Dalam rangka memperluas segmentasi pasar UKM Canggi Fully ingin membuat kemasan premium sehingga dilakukan perbaikan desain kemasan biskuit brownies Cripyx. Kemasan premium yang diharapkan adalah kemasan dengan desain grafis yang lebih menarik, memiliki bahan kemasan yang tahan tumpukan dan ergonomis serta penambahan kapasitas produk menjadi lebih besar. Salah satu metode yang dapat digunakan untuk perbaikan desain kemasan, yaitu metode Quality Function Deployment (QFD). QFD berfungsi untuk menentukan atribut apa saja yang akan memuaskan pelanggan dan menerjemahkannya ke dalam target desain sehingga penerapan QFD dapat mengurangi panjang siklus pengembangan produk, yang mana dalam hal ini kemasan, sekaligus meningkatkan kualitas dan pemasaran produk di pasar.

\section{METODE}

Penelitian ini dilakukan di UKM Canggi Fully, Kota Malang, Jawa Timur. Pengolahan data dilakukan pada bulan Februari - Juli 2019. Responden pada penelitian ini adalah pelanggan dan pembeli biskuit brownies Cripyx. Instrumen penelitian yang digunakan adalah kuesioner kepentingan, harapan dan kepuasaan pelanggan serta kuesioner produsen dengan menggunakan simbol hubungan atribut dan kebutuhan pelanggan serta kuesioner simbol hubungan antar respon teknis dan perhitungan dilakukan menggunakan software SPSS versi 16.0.

\section{Identifikasi Variabel}

Tahap identifikasi variabel bertujuan untuk menentukan atribut pelanggan (Whats) dan kemampuan teknis (Hows) yang dimiliki UKM Canggi Fully untuk memenuhi Customer Needs. Variabel yang menjadi objek penelitian ini adalah kemasan produk biskuit brownies Cripyx. Pada survei pendahuluan didapatkan atribut pelanggan dari pihak produsen melalui wawancara dengan pemilik UKM dan studi literatur oleh peneliti yang ditunjukkan pada Tabel 1.

Tabel 1. Atribut Whats

\begin{tabular}{|c|c|c|}
\hline \multicolumn{3}{|c|}{ Harapan Pelanggan (Whats) } \\
\hline No. & Atribut Pelanggan & Respon Teknis \\
\hline 1 & Desain Grafis Kemasan & $\begin{array}{l}\text { Inovasi Kemasan } \\
\text { Baru Biskuit } \\
\text { Brownies Premium }\end{array}$ \\
\hline 2 & Dimensi Kemasan & $\begin{array}{l}\text { Kesesuaian ukuran } \\
\text { kemasan terhadap } \\
\text { produk }\end{array}$ \\
\hline 3 & Kapasitas Kemasan & $\begin{array}{l}\text { Kapasitas Kemasan } \\
\text { Biskuit Brownies } \\
\text { Premium yang } \\
\text { sesuai }\end{array}$ \\
\hline 4 & Bentuk Kemasan & $\begin{array}{l}\text { Kemasan Biskuit } \\
\text { Brownies Premium } \\
\text { yang ergonomis }\end{array}$ \\
\hline 5 & Kekuatan Kemasan & $\begin{array}{l}\text { Kemasan Biskuit } \\
\text { Brownies Premium } \\
\text { tahan tumpukan }\end{array}$ \\
\hline 6 & Ketahanan Kemasan & $\begin{array}{l}\text { Kemasan Biskuit } \\
\text { Brownies Premium } \\
\text { tidak mudah rusak }\end{array}$ \\
\hline
\end{tabular}

Sumber: Data primer diolah (2019)

\section{Analisa Data QFD}

Pada penelitian ini digunakan analisis data menggunakan metode Quality Function Deployment (QFD) hanya sampai tahap pembuatan House of Quality (HoQ). Analisis ini dilakukan untuk mengolah data dan menyesuaikan dengan kebutuhan penelitian terkait perbaikan desain kemasan produk. Menurut Suryaningrat dkk. (2010), tahapan analisis data menggunakan QFD adalah sebagai berikut:

\section{a. Tahap Pengumpulan Voice of Customer}

Pada tahap ini voice of customer diperoleh dengan menggunakan survei seperti wawancara dan penyebaran kuesioner. Proses ini akan menghasilkan atribut-atribut kemasan produk yang dapat diterima pelanggan. Pada tahap ini peneliti akan mengidentifikasi semua kebutuhan dan keinginan pelanggan terhadap kemasan produk biskuit brownies yang ditawarkan. Tiap atribut mempunyai beberapa data numerik yang berkaitan dengan kepentingan atribut bagi pelanggan, dan tingkat performansi kepuasan pelanggan dari produk yang serupa berdasarkan atribut tersebut (Marvin et al., 2011).

\section{b. Tahap Penyusunan House of Quality (HoQ)}

Dalam pembuatan House of Quality terdiri dari beberapa tahapan antara lain sebagai berikut:

1. Tahap I pembuatan matriks kebutuhan pelanggan, dimana pada tahap ini peneliti akan turun ke lapang dan berinteraksi dengan pelanggan untuk mengumpulkan data kualitatif berupa keinginan dan kebutuhan pelanggan terhadap kemasan biskuit brownies Cripyx dan menyusunnya menjadi atribut kepentingan pelanggan yang akan diterjemahkan ke dalam upaya perbaikan teknis (Hows) yang menunjukkan bagaimana pihak UKM akan memenuhi keinginan pelanggan.

2. Tahap II pembuatan matriks perencanaan, dimana pada tahap ini peneliti akan mengukur kebutuhan pelanggan dan menetapkan tujuan perfomansi kepuasaan dalam bentuk nilai. Pembuatan matriks perencanaan meliputi perhitungan nilai importance to customer, nilai customer satisfaction perfomance, nilai goal, nilai improvement ratio, penentuan sales point, perhitungan raw weight dan normalized raw weight. Dalam perhitungan yang dilakukan dalam House of Quality nilai harus selalu diperiksa secara konsisten agar tidak terjadi kesalahan.

3. Tahap III pembuatan respon teknis, dimana pada tahap ini dilakukan transformasi dari kebutuhan pelanggan yang bersifat non teknis menjadi data yang bersifat teknis. Respon teknis tersebut digunakan pihak UKM untuk memenuhi customer needs berdasarkan atribut kemasan produk yang telah diketahui.

4. Tahap IV penentuan hubungan respon teknis dengan kebutuhan pelanggan, dimana pada penelitian ini peneliti akan menentukan seberapa kuat hubungan antara respon teknis dengan kebutuhan pelanggan dalam bentuk simbol. Simbol hubungan yang digunakan dapat dilhat pada Tabel 2. Hubungan teknis ditentukan untuk memudahkan dalam menentukan keputusan yang akan diambil. Dalam menentukan hubungan teknis digunakan simbol. Simbol hubungan antar respon teknis dapat dilihat pada Tabel 3. 
Tabel 2. Simbol Hubungan Atribut Whats dengan Hows

\begin{tabular}{clc}
\hline Simbol & \multicolumn{1}{c}{ Keterangan } & Nilai \\
\hline & Hubungan Kuat & 9 \\
& Hubungan Sedang & 3 \\
Kosong & Hubungan Lemah & 1 \\
\hline
\end{tabular}

Sumber : Prasetyo dan Arifin (2016)

Tabel 3. Simbol Hubungan antar Respon Teknis

\begin{tabular}{clc}
\hline Simbol & \multicolumn{1}{c}{ Keterangan } & Nilai \\
\hline++ & Hubungan Kuat Positif & +9 \\
+ & Hubungan Positif & +3 \\
Kosong & Tidak ada hubungan & 0 \\
- & Hubungan Negatif & -3 \\
-- & Hubungan Kuat Negatif & -9 \\
\hline
\end{tabular}

Sumber : Prasetyo dan Arifin (2016)

5. Tahap $\mathbf{V}$ penentuan tingkat kesulitan dan korelasi teknis, dimana penentuan tingkat kesulitan dilakukan dengan memprioritaskan atribut kemasan yang perlu dilakukan perbaikan. Pada tahap ini peneliti akan memetakan hubungan dan kepentingan antara karakteristik kualitas pengganti atau respon teknis yang sudah didapat kemudian ditentukan direction of goodness lalu dilakukan perhitungan nilai kontribusi dan penentuan ranking. Keseluruhan karakteristik tersebut akan dijadikan pertimbangan untuk menentukan atribut mana yang menjadi prioritas untuk dilakukan perbaikan. Penentuan tingkat kesulitan ini diambil dari sudut pandang pihak UKM agar lebih representatif.

6. Tahap VI benchmarking, dimana nilai benchmarking yang dihasilkan akan digunakan untuk menentukan respon teknis mana yang ingin dijadikan prioritas oleh pihak UKM dan perbaikan seperti apa yang akan dilakukan berdasarkan informasi langsung dari pelanggan. Dalam penelitian ini dilakukan benchmarking terhadap kemasan yang sudah ada dan kemasan harapan konsumen. penentuan nilai benchmarking dilakukan untuk mengetahui nilai kinerja yang harus dilakukan pihak UKM untuk memenuhi kebutuhan konsumen terhadap kemasan biskuit brownies.

7. Tahap VII penentuan nilai target, dimana target penentuan kemasan yang akan ditentukan adalah yang dianggapp baik dan dapat menarik daya beli pelanggan. Nilai target tesebut ditentukan oleh pemilik UKM. Dalam menentukan target pemilik dibantu oleh peneliti dalam memberikan referensi dan usulan perbaikan.

\section{c. Tahap analisa dan interpretasi}

Tahap analisa dan interpretasi merupakan tahap pengimplementasian Quality Function Deployment secara teknis. Pada tahap ini dilakukan analisa dan interpretasi terhadap House of Quality yang telah disusun. Berdasarkan analisa tersebut akan dihasilkan desain kemasan produk baru yang mempunyai karakteristik kuat dalam memenuhi keinginan pelanggan.

\section{Penentuan Responden}

Sampel merupakan satuan penelitian yang digunakan dalam pengambilan data dimana hanya dibutuhkan sebagian dari populasi untuk dijadikan sampel penelitian. Responden yang digunakan adalah yang pernah membeli dan mengonsumsi produk. Penentuan responden yang digunakan dalam penelitian menggunakan teknik non probability sampling dengan jenis accidental sampling, artinya siapa saja pembeli biskuit brownies Cripyx yang tidak sengaja bertemu dengan peneliti dan sesuai dengan karakteristik maka orang tersebut dapat digunakan sebagai responden. Jumlah sampel ditentukan dengan menggunakan pendekatan Linier Time Function. Pengambilan sampel berdasarkan linier time function dapat dilakukan bila jumlah populasinya tidak diketahui secara pasti. Dalam penelitian ini, kegiatan pengambilan sampel responden dilakukan selama 20 hari karena waktu tersebut dinilai cukup untuk mendapatkan informasi yang dibutuhkan. Besarnya sampel yang dihitung berdasarkan Linear Time Function dengan rumus sebagai berikut:

$n=\frac{T-t o}{t 1}$

Keterangan:

$\mathrm{n}$ : jumlah sampel

$\mathrm{T}$ : waktu yang tersedia untuk penelitian $=(20$ hari $\mathrm{x} 12 \mathrm{jam})$ $=240$ jam

to: waktu tetap tidak tergantung pada besarnya sampel, yaitu waktu dimana pengambilan sampel tidak tergantung pada besarnya sampel) (2 jam/hari x 20 hari $=40 \mathrm{jam})$

$t_{1}$ : Waktu yang digunakan responden untuk mengisi kuesioner $(0,25 \times 20$ hari $=5$ jam $)$

$n=\frac{240-40}{5}=40$

Dalam penelitian ini digunakan jumlah responden sebanyak 40 orang. Menurut Sugiyono (2011), ukuran sampel yang layak digunakan untuk penelitian adalah antara 30 sampai dengan 500 orang. Syarat untuk menjadi responden antara lain adalah berusia 17 tahun keatas karena sampel pada umur tersebut dinilai representatif dalam memberikan suatu penilaian (Putri dkk., 2015).

\section{HASIL DAN PEMBAHASAN}

\section{Profil UKM}

Canggi Fully merupakan UKM yang bergerak di bidang industri bakery jenis pastry dan kue kering. Usaha tersebut didirikan oleh Ibu Canggi Fully Solidaritas pada tahun 2016 di Jalan Bandulan Gang 8 RT 07 RW 01 Malang, Jawa Timur. Pemilik menggunakan modal pribadi untuk mendirikan usaha ini dengan modal sebesar Rp500.000,00 untuk pembuatan produk pertama kali. Sebelumnya, pemilik pernah belajar mengenai cara pengolahan bakery pada masa kuliah di Universitas Negeri Malang jurusan tata boga, sehingga mampu mengembangkan beberapa jenis pastry dan kue kering.

UKM Canggi Fully saat ini baru memiliki dua orang tenaga kerja yang ditempatkan pada bagian produksi. Pada awal tahun 2016, UKM ini hanya memproduksi Brownies Pie dan berproduksi secara manual dengan fasilitas alat dapur berupa satu oven panggang. Brownies Pie merupakan olahan brownies yang memiliki umur simpan yang sangat singkat yaitu sekitar dua minggu setelah proses produksi. Pada akhir tahun 2016 pemilik melakukan inovasi produk dengan membuat olahan kue brownies kering dengan umur simpan lebih lama yang diberi nama Brownie Kring.

Pada tahun 2017 UKM Canggi Fully menambah varian produk biskuit brownies Cripyx yang merupakan produk 
unggulan karena memiliki banyak peminat. Pada awal tahun 2018 beberapa mitra UKM tertarik untuk membeli produk ini untuk dijual kembali (reseller) sehingga saat ini brownies Cripyx sudah dijual oleh beberapa mitra UKM di Malang. Produk biskuit brownies Cripyx akan menjadi objek yang akan diteliti untuk diperbaiki desain kemasannya. Kemasan biskuit brownies Cripyx ditunjukkan pada Gambar 1.

Pada awal tahun 2018 Canggi Fully menambah varian produk moringa chips dan kue sus. Moringa chips merupakan keripik dengan taburan daun kelor (moringa) kering yang mana produk ini juga pernah memenangkan perlombaan inovasi olahan daun kelor yang diadakan oleh pemerintah setempat. Kue sus dengan merek dagang ini sus zhu juga merupakan olahan bakery yang memiliki banyak peminat di berbagai kalangan usia. Kue sus ini disajikan dengan berbagai varian rasa seperti vanilla, cokelat dan durian.

Visi dari Canggi Fully yaitu menjadi tempat tujuan membeli produk bakery di Kota Malang, sedangkan misinya menjadi usaha pangan dengan rasa dan kualitas produk terbaik. Proses pemasaran yang dilakukan oleh Canggi Fully yaitu secara online maupun offline. Pemasaran online dilakukan melalui media sosial seperti whatshapp dan instagram sedangkan pemasaran offline dilakukan dengan membuka stand di CFD (Car Free Day) di Jalan ljen Malang setiap hari minggu. Omzet yang didapatkan dari penjualan bakery sebesar 10 juta per bulan.

Keunggulan produk yang ditawarkan UKM Canggi Fully adalah bahan yang digunakan adalah bahan dengan kualitas tinggi karena Canggi Fully memiliki tagline perusahaan yaitu bahan berkualitas. Keunggulan lainnya adalah produk Canggi Fully tidak menggunakan bahan tambahan pangan yang berbahaya untuk kesehatan seperti pemanis buatan dan pewarna makanan. UKM Canggi Fully juga sudah memiliki izin pemasaran dengan nomor P-IRT 2063573102561-22 sehingga dapat dipastikan bahwa produk UKM Canggi Fully aman dikonsumsi.

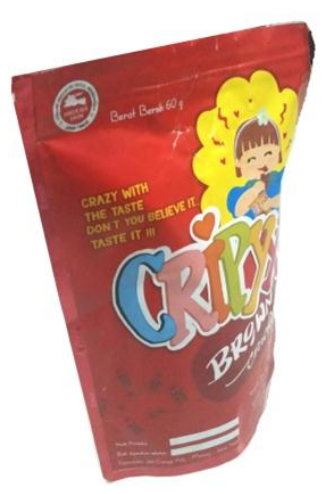

Gambar 1. Kemasan Biskuit Brownies Cripyx

(Sumber: UKM Canggi Fully, 2019)

\section{Karakteristik Responden}

Responden pada penelitian ini adalah pembeli dan pelanggan biskuit brownies Cripyx sebanyak 40 orang. Karakteristik responden berdasarkan usia, jenis, kelamin, pekerjaan, pendidikan terakhir, pendapatan serta frekuensi pembelian dapat dilihat pada Tabel 4. Berdasarkan usia pembeli brownies Cripyx yang tertinggi yaitu pada rentang 17-25 tahun dengan persentase $75 \%$. Hal tersebut sesuai dengan literatur menurut Ebert (2010) bahwa konsumen muda (dibawah usia 30 tahun) lebih berminat untuk mencoba sesuatu yang baru, karena cenderung memiliki rasa ingin tahu yang lebih besar terhadap hal-hal baru. Berdasarkan jenis kelamin pembeli brownies Cripyx dengan jumlah terbanyak adalah perempuan dengan persentase $70 \%$. Hal tersebut sesuai dengan literatur menurut Kotler (2017) bahwa konsumen dengan jenis kelamin perempuan lebih cepat mengambil keputusan dalam membeli produk baru dan cenderung lebih konsumtif dalam hal berbelanja.

Tabel 4. Karakteristik Responden

\begin{tabular}{|c|c|c|c|c|}
\hline No & Keterangan & Karakteristik & Jumlah & Persentase (\%) \\
\hline \multirow[t]{3}{*}{1} & Usia & a. $17-25$ tahun & 30 & 75 \\
\hline & & b. $26-50$ tahun & 6 & 15 \\
\hline & & c. $51-65$ tahun & 4 & 10 \\
\hline \multirow[t]{2}{*}{2} & Jenis Kelamin & a. Laki-laki & 12 & 30 \\
\hline & & b. Perempuan & 28 & 70 \\
\hline \multirow[t]{6}{*}{3} & Peker-jaan & a. Pelajar/ & 30 & 75 \\
\hline & & Mahasiswa & 4 & 10 \\
\hline & & b. PNS & 2 & 5 \\
\hline & & c. Pegawai Swasta & 2 & 5 \\
\hline & & d. Wiraswasta & 2 & 5 \\
\hline & & e. Lainnya & & \\
\hline \multirow[t]{2}{*}{4} & Pendi-dikan Terakhir & a. SMA/SMK & 31 & 82,5 \\
\hline & & b. $S 1 / S 2$ & 7 & 17,5 \\
\hline \multirow[t]{5}{*}{5} & Penda-patan Per Bulan & a. $<\operatorname{Rp} 500.000,00$ & 9 & 22,5 \\
\hline & & b. Rp500.000,00 - Rp1.000.000,00 & 8 & 20 \\
\hline & & C. Rp1.000.000,00 - Rp1.500.000,00 & 7 & 17,5 \\
\hline & & d. Rp1.500.000 - Rp2.000.000,00 & 5 & 12,5 \\
\hline & & e. $>$ Rp2.000.000,00 & 11 & 27,5 \\
\hline \multirow[t]{2}{*}{6} & Fre-kuensi Pembelian & a. 1-2 kali & 27 & 67,5 \\
\hline & & b. $>2$ kali & 13 & 32,5 \\
\hline
\end{tabular}

Keterangan: Angka yang bercetak tebal adalah nilai dengan persentase terbesar Sumber: Data primer diolah (2019) 
terakhir pembeli brownies Cripyx diketahui bahwa mayoritas responden memiliki pendidikan terakhir SMA/SMK dengan persentase sebesar $82,5 \%$. Menurut Kalsum et al. (2013) tingkat pendidikan SMA sampai perguruan tinggi lebih banyak mempunyai pengetahuan dan pengalaman mengenai makanan/cemilan yang unik, sehat dan bergizi. Berdasarkan pekerjaan pembeli brownies Cripyx dengan jumlah terbanyak adalah pelajar/mahasiswa dengan presentase $75 \%$ yang mana hal tersebut sesuai dengan literatur Gaikwad et al. (2017) mahasiswa suka mencari referensi makanan dengan tampilan yang menarik dan harga yang terjangkau. Berdasarkan pendapatan per bulan pembeli brownies Cripyx didapatkan hasil yang variatif dan tidak terlalu signifikan. Hasil menunjukkan bahwa responden dengan penghasilan lebih dari Rp2.000.000,00 memiliki nilai persentase terbesar yaitu $27,5 \%$ di sisi lain responden dengan pendapatan per bulan kurang dari Rp500.000,00 memiliki persentase $22,5 \%$, hal tersebut menunjukkan bahwa biskuit brownies Cripyx dapat dinikmati oleh berbagai kalangan mulai dari menengah ke bawah hingga menengah ke atas.

\section{Pembuatan House of Quality}

Pembuatan House of Quality dilakukan dengan beberapa tahap dimulai dari pembuatan matriks kebutuhan yang telah dibuat di awal penelitian. Data didapatkan melalui wawancara dengan pihak produsen. Penyusunan House of Quality dilanjutkan dengan pembuatan importance to customer, customer satisfaction perfomance, goal, improvement ratio, sales point, raw weight, normalized raw weight, dan pembuatan respon teknis yang saling berhubungan. Hasil pembuatan house of quality dapat dilihat pada Gambar 2.

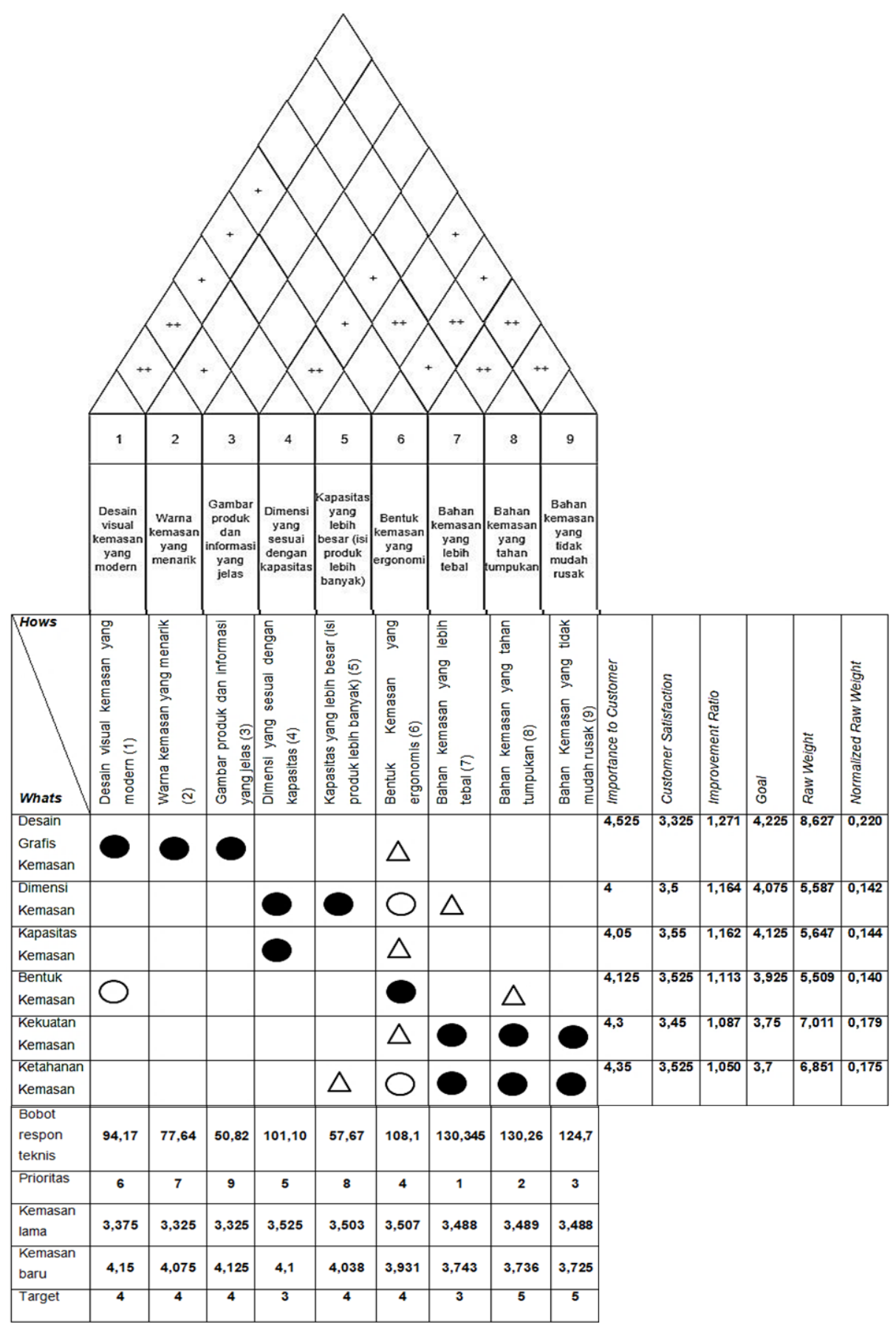

Gambar 2. House of Quality 


\section{Pembuatan Respon Teknis}

Respon teknis didapatkan dari beberapa saran yang diberikan konsumen untuk perbaikan desain kemasan biskuit brownies serta wawancara dengan pihak produsen terkait cara untuk memenuhi keinginan konsumen terhadap kemasan biskuit brownies yang baru. Menurut Bennur dan
Jin (2012), pada tahap pembuatan respon teknis, peneliti akan memunculkan solusi berupa respon (secara teknis) terhadap voice of customer untuk memenuhi keinginan pelanggan. Respon teknis yang telah dilakukan oleh pindah produsen dalam memproduksi kemasan dapat dilihat pada Tabel 5 .

Tabel 5. Respon Teknis

\begin{tabular}{cll}
\hline No. & Atribut Pelangan (Whats) & \multicolumn{1}{c}{ Respon Teknis (Hows) } \\
\hline 1 & Desain Grafis Kemasan & $\begin{array}{l}\text { Desain grafis kemasan visual yang modern } \\
\text { Warna yang menarik }\end{array}$ \\
& & Gambar produk dan informasi yang lebih jelas \\
2 & Dimensi Kemasan & Dimensi dan ukuran kemasan yang sesuai dengan kapasitas produk \\
3 & Kapasitas Kemasan & Kapasitas lebih besar (isi produk lebih banyak) \\
4 & Bentuk Kemasan & Bentuk kemasan yang ergonomis \\
5 & Kekuatan Kemasan & Bahan kemasan yang lebih tebal \\
& & Bahan kemasan tidak mudah rusak \\
6 & Ketahanan Kemasan & Bahan kemasan tahan tumpukan \\
\hline
\end{tabular}

Sumber: Data primer diolah (2019)

\section{Perancangan Desain Kemasan Baru}

Pembuatan desain kemasan produk yang baru dilakukan dengan melihat hasil pengolahan data dengan metode QFD dan hasil dari pembuatan House of Quality yang dapat dilihat pada Gambar 2. Dalam merancang desain kemasan baru diperhatikan respon teknis yang menjadi prioritas perbaikan desain dan hubungan antar atribut whats dan hows yang sudah ditentukan. Atribut dengan hubungan yang kuat akan menjadi prioritas perbaikan dan dilanjutkan menggunakan atribut dengan hubungan yang sedang dan lemah.

Pada desain kemasan biskuit brownies Cripyx yang baru diberi desain lebih modern dan eksklusif sesuai dengan keinginan konsumen yang kebanyakan merupakan kalangan muda. Desain grafis kemasan premium dibuat dengan campuran warna cream, cokelat, dan merah. Perpaduan ketiga warna tersebut dinilai serasi dengan beberapa gambar tampilan produk ditampilkan. Desain grafis kemasan dapat dilihat pada Gambar 3. Penambahan gambar produk dan pemilihan warna kontras membuat kemasan terlihat lebih menarik. Hal tersebut sesuai dengan pendapat (Mohebbi, 2014) yang mengatakan bahwa kalangan muda menyukai kemasan yang terlihat kontras dan memiliki gambar yang menarik. Penggunaan warna cokelat, merah dan krem merupakan pemilihan warna yang kontras sehingga direkomendasikan dalam sebuah kemasan karena dapat meningkatkan daya tarik pembeli terhadap sebuah produk.

Menurut Peraturan Badan Pengawas Obat dan Makanan nomor 31 tahun 2018 tentang label pangan olahan untuk pencantuman label ditulis atau dicetak dengan menggunakan bahasa Indonesia disertai pencantuman informasi kandungan bahan, informasi nilai gizi, asal usul produk, tempat produksi, pelaku usaha pangan, nama produk, berat bersih atau isi bersih, halal bagi yang dipersyaratkan, tanggal dan kode produksi, nomor izin edar bagi pangan olahan serta tanggal, bulan dan tahun kadaluarsa. Dalam kemasan baru terdapat deskripsi produk, berat produk, nomor P-IRT, komposisi produk, tanggal kadaluwarsa dan kode produksi. Pada desain kemasan biskuit brownies premium beberapa keterangan yang dicantumkan sudah sesuai dengan peraturan tersebut. Kemasan baru juga ditambahkan tagline menarik yaitu "Gaya Baru Menikmati Brownies", logo buang sampah pada tempatnya dan logo 100\% Indonesia untuk meningkatkan kesadaran konsumen Indonesia untuk lebih mengapresiasi dan mempromosikan produk hasil karya anak bangsa Indonesia.

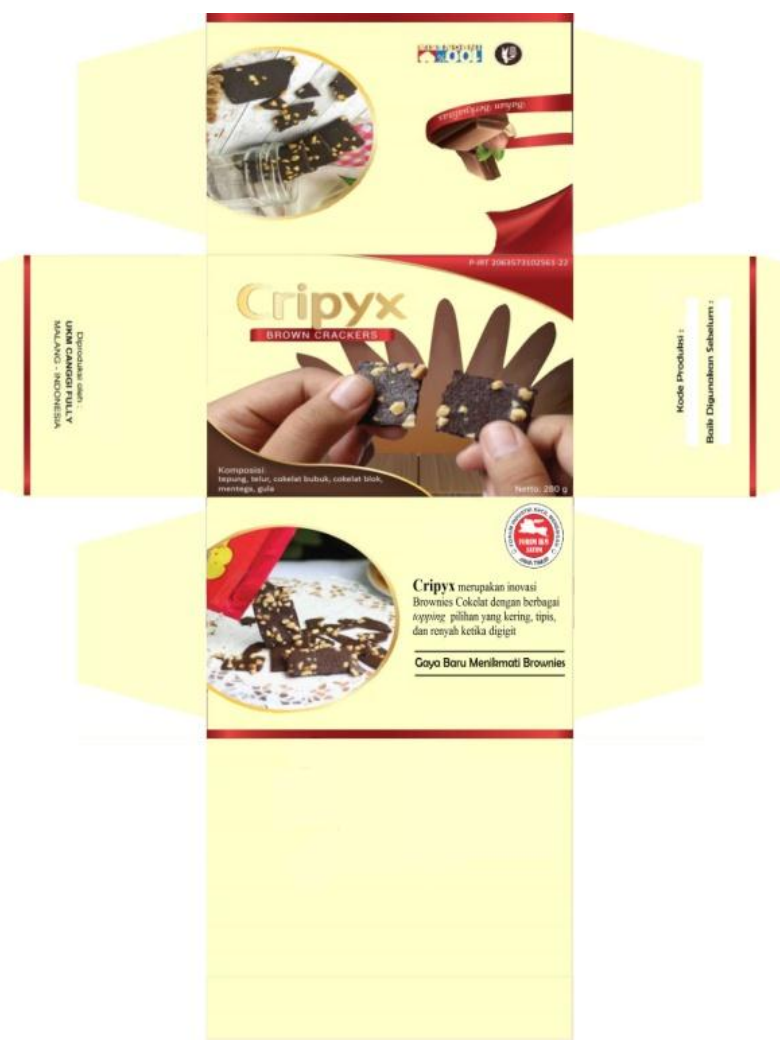

Gambar 3. Desain Grafis Kemasan Baru

Pada atribut dimensi kemasan, desain produk yang baru yang merupakan kemasan sekunder dibuat dengan panjang $14 \mathrm{~cm}$, lebar $8 \mathrm{~cm}$ dan tinggi $7 \mathrm{~cm}$. Ukuran tersebut sesuai dengan kapasitas kemasan dan bentuk kemasan primer baru yang merupakan toples dengan bahan plastik mika berbentuk persegi panjang dengan dimensi $14 \mathrm{~cm}$, lebar $7 \mathrm{~cm}$ dan tinggi $7 \mathrm{~cm}$ yang ditunjukan pada Gambar 4 . Berdasarkan analisa pengolahan data diketahui bahwa konsumen menginginkan produk dengan kapasitas yang besar dan isi yang lebih banyak, sehingga pada kemasan baru dibuat produk dengan isi bersih (netto) 280 gram yang 
semula hanya 60 gram. Dengan penambahan kapasitas yang lebih besar tersebut mengakibatkan bentuk kemasan biskuit brownies diubah menjadi persegi panjang atau balok menggunakan toples plastik dan dikemas menggunakan kertas art paper laminasi doff sebagai kemasan sekunder.

Tabel 6. Konsep Terpilih

\begin{tabular}{lll}
\hline \multicolumn{1}{c}{ Atribut Kemasan } & \multicolumn{1}{c}{ Spesifikasi Kemasan } & \multicolumn{1}{c}{ Konsep Terpilih } \\
\hline Desain Grafis Kemasan & Warna & Kombinasi warna krem, cokelat, merah \\
Dimensi Kemasan & Ukuran Kemasan Primer & $14 \mathrm{~cm} \mathrm{\times 7} \mathrm{cm} \mathrm{x} 7 \mathrm{~cm}$ \\
& Ukuran Kemasan Sekunder & $14 \mathrm{~cm} \times 8 \mathrm{~cm} \times 7 \mathrm{~cm}$ \\
Bentuk Kemasan & Kemasan Primer & Toples Plastik Persegi Panjang \\
& Kemasan Sekunder & Persegi Panjang \\
Kapasitas Kemasan & Isi produk & 280 gram \\
Kekuatan Kemasan & Nama bahan & Kertas art paper gramatur 260 gram \\
Ketahanan Kemasan & Lapisan kertas & Laminasi doff \\
\hline Sumber: &
\end{tabular}

Sumber: Data primer diolah (2019)

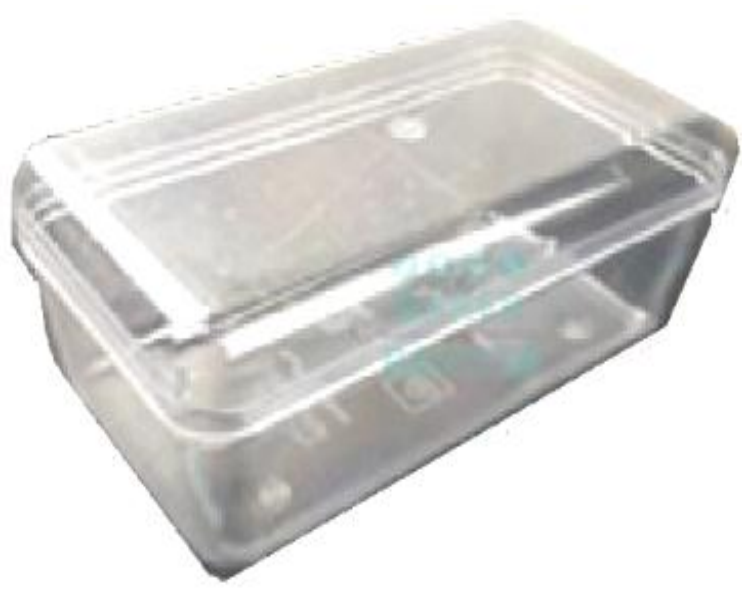

Gambar 4. Tampak Samping Kemasan Primer (Sumber: UKM Canggi Fully, 2019)

Berdasarkan prioritas perbaikan desain diketahui bahwa konsumen menginginkan bahan yang lebih tebal, tahan tumpukan dan tidak mudah rusak. Pada kemasan biskuit brownies yang lama digunakan kemasan primer berbahan aluminium foil dengan bentuk pouch, jadi untuk kemasan baru digunakan kemasan primer toples plastik dan kemasan sekunder berupa kertas art paper dengan gramatur 260 gram. Konsumen juga menginginkan kemasan yang tidak mudah rusak, sehingga ditambahkan laminasi doff pada kertas art paper agar dasarnya tidak mudah kotor dan lecek. Desain kemasan baru terpilih dapat dilihat pada Tabel 6. Tampak samping kemasan sekunder biskuit brownies cripyx yang baru dapat dilihat pada Gambar 5.

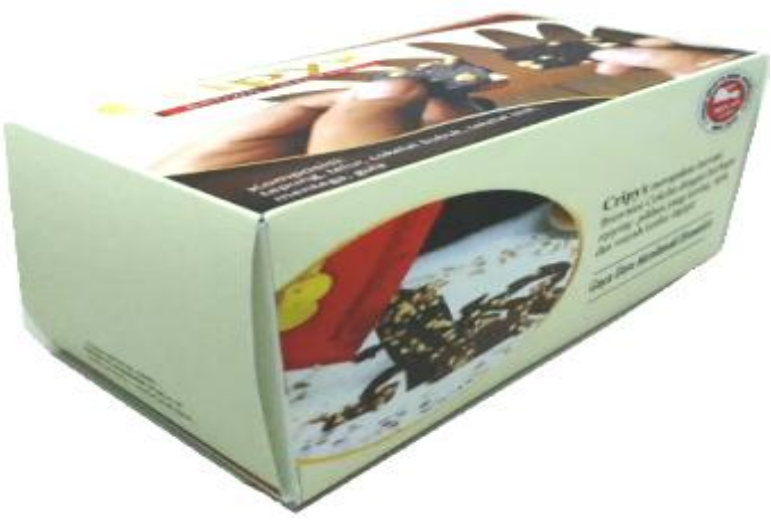

Gambar 5. Tampak Samping Kemasan Sekunder

\section{Verifikasi User}

Pada tahap verifikasi user peneliti mempertanyakan bagaimana tanggapan pihak UKM terhadap usulan perancangan desain kemasan biskuit brownies premium yang telah dibuat. Berdasarkan beberapa kali konsultasi terkait desain produk yang diberikan peneliti, pihak UKM setuju untuk menggunakan desain kemasan dengan campuran warna krem, cokelat dan merah dengan dimensi panjang $14 \mathrm{~cm}$, lebar $8 \mathrm{~cm}$ dan tinggi $7 \mathrm{~cm}$. Pihak UKM juga menyetujui untuk membuat kemasan kapasitas isi lebih banyak yaiitu sebesar 280 gram dan bentuk kemasan yang dibagi menjadi kemasan primer dan kemasan sekunder. Kemasan primer berbentuk toples plastik dan dilapisi oleh kertas art paper laminasi doff sebagai kemasan sekunder. Kemasan biskuit brownies premium yang dapat diterima produsen dan konsumen ditunjukkan pada Gambar 6 .

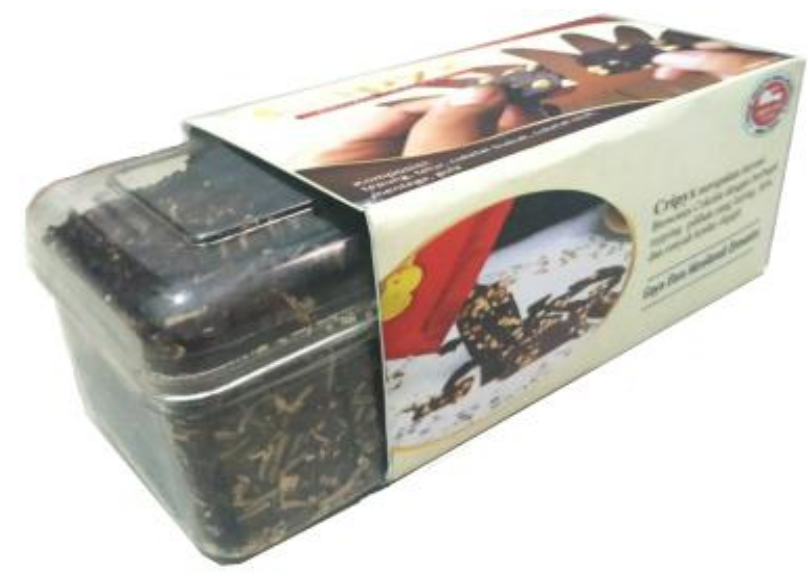

Gambar 6. Kemasan Biskuit Brownies Cripyx Premium

Kemasan baru terbuat dari bahan yang kuat sehingga kemasan ini dapat memenuhi keinginan konsumen terhadap bahan kemasan lebih tebal dan tahan tumpukan. Kemasan baru juga memungkinkan produsen untuk melakukan pengiriman keluar kota karena bahan yang digunakan mampu melindungi isi produk dari guncangan selama perjalanan. Desain visual dari kemasan baru juga sudah memuat berbagai informasi dan gambar yang dapat meningkatkan minat konsumen pada produk biskuit brownies Cripyx premium. Penggunaan kemasan toples dilapisi kemasan sekunder dengan tambahan berbagai gambar dan perpaduan warna kontras membuat kemasan baru lebih menarik karena sesuai keinginan konsumen. Perpaduan gambar dan warna yang digunakan juga 
membuat kemasan baru terlihat lebih elegan dan modern. Segmentasi pasar dari kemasan baru ini diharapkan juga meningkat menjadi menengah ke atas seperti pegawai negeri, ibu rumah tangga, dan wisatawan dimana secara harga yang dipasok juga meningkat dan tetap sesuai nilai jual produk yang diberikan. Kemasan premium yang baru juga turut menyelesaikan permasalahan kemasan lama yang mudah kusut dan kurang kokoh untuk melindungi isi produk.

\section{KESIMPULAN}

Rancangan desain kemasan biskuit brownies premium yang dapat diterima oleh UKM Canggi Fully adalah kemasan primer berupa toples plastik berbentuk persegi panjang dan kemasan sekunder berupa kertas art paper laminasi doff dengan gramatur kertas 260 gram dan dimensi kemasan panjang $14 \mathrm{~cm}$, lebar $8 \mathrm{~cm}$, dan tinggi 7 $\mathrm{cm}$ dengan desain grafis menggunakan perpaduan warna krem, cokelat dan merah. Kapasitas produk yang diterima oleh konsumen dan pihak UKM adalah dengan netto 280 gram. Kemasan baru terbuat dari bahan yang tebal sehingga memungkinkan produsen untuk melakukan pengiriman keluar kota karena bahan yang digunakan mampu melindungi isi produk dari guncangan selama perjalanan. Kemasan premium baru juga turut menyelesaikan permasalahan kemasan lama yang mudah kusut dan kurang kokoh untuk melindungi isi produk. Perpaduan gambar dan warna yang digunakan membuat kemasan baru terlihat lebih elegan dan modern. Segmentasi pasar dari kemasan baru ini juga turut meningkat menjadi menengah ke atas seperti pegawai negeri, ibu rumah tangga, dan wisatawan dimana secara harga yang dipasok juga meningkat sesuai nilai jual produk yang diberikan.

\section{DAFTAR PUSTAKA}

Bennur, S. and Jin, B. (2012). A conceptual process of implementing quality apparel retail store attributes: an application of kano's model and the quality function deployment approach. International Journal of Business Humanities and Technology. 2(1): 174-183

Ebert, R. J. 2010. Bisnis, Edisi 8. Erlangga. Jakarta

Gaikwad, S.T., Saxena, V., Kamble, D.B., Upadhyay, A. (2017). Investigating consumer preference of college students about food for fasting. International Journal of Management Research. 5(1): 126-138

Kotler, P. (2017). Marketing for Competitiveness. Bentang. Yogyakarta.

Kalsum, U. E.. Fauziyah, dan T.R.D.A. Nugroho. (2013). Preferensi Konsumen Dalam Membeli Rengginang Lorjuk di Kecamatan Kamal Bangkalan. Jurnal Agriekonomika. 2(2): 153-162

Marvin, E.G., Gioconda, Q., James, M., Rene, D.M. (2011). International business curriculum design: identifying the voice of the customer using QFD. Journal of International Education in Business. 4(1): 6-29.

Mohebbi, B. (2014). The art of packaging: an investigation in the role of color in packaging, marketing and branding. International Journal of Organization Leadership. 3(2). 92-102

Prasetyo, A dan Arifin, M.Z. (2016). House Of Quality Kampung Organik. Indocamp. Jakarta.

Pusat Data dan Sistem Informasi Pertanian. (2015). Dilihat $18 \quad$ Maret 2019. http://epublikasi.setjen.pertanian.go.id/epublikasi/Statist
ikPertanian/2015/STATISTIK\%20KONSUMSI\%20PAN GAN\%202015/files/assets/basic-html/page126.html

Putri, A., Effendi, U., Effendi, M. (2015). Analisis Perencanaan Strategi Peningkatan Kualitas Pelayanan Pelanggan Dengan Metode Quality Function Deployment (QFD). Jurnal Industria. 4(1): 41-52.

Sugiyono. (2011). Metode Penelitian Kuantitatif, Kualitatif dan R\&D. Alfabeta. Bandung.

Suryaningrat, I.B., Djumarti, E., Ruriani dan Kurniawati, I. (2010). Aplikasi Metode Quality Function Deployment (QFD) unuk Peningkatan Kualitas Produk Mie Jagung. Jurnal Agrotek. 4(1):8-17. 